\title{
MOVIMENTO SINDICAL: O DESAFIO DE IDENTIFICAR, ATRAIR, DESENVOLVER NOVAS LIDERANÇAS EM UM AMBIENTE DE TRANSFORMAÇÃO DAS RELAÇÕES TRABALHISTAS
}

\section{ARTIGO ORIGINAL}

MENEZES, Alexsander Soares ${ }^{1}$

SELVA, Carlos Alberto La ${ }^{2}$

MENEZES, Alexsander Soares. SELVA, Carlos Alberto La. Movimento Sindical: 0 desafio de identificar, atrair, desenvolver novas lideranças em um ambiente de transformação das relações trabalhistas. Revista Científica Multidisciplinar Núcleo do Conhecimento. Ano 06, Ed. 01, Vol. 01, pp. 49-67. Janeiro de 2021. ISSN: 24480959, Link de

acesso: https://www.nucleodoconhecimento.com.br/administracao/movimentosindical

\section{RESUMO}

O presente artigo apresenta uma análise conjuntural da atuação sindical pós reforma trabalhista, dentro da perspectiva de sua existência como uma organização, estabelecendo paralelos entre os sindicatos e organizações convencionais, contextualizando suas deficiências históricas na identificação, atração, formação e renovação dos seus quadros de liderança. Objetiva-se com este artigo indicar ações que potencializem as competências das lideranças sindicais, em consonância com as práticas de capacitações utilizadas por organizações convencionais, possibilitando reduzir suas fraquezas, neutralizando ameaças e explorando as oportunidades identificadas ao longo do seu desenvolvimento. Para a elaboração deste artigo foram

\footnotetext{
${ }^{1}$ Pós-Graduado em Gestão de Pessoas e Liderança - Universidade Cândido Mendes e Graduado em Administração de Empresas - Universidade Católica de Brasília.

${ }^{2}$ Orientador.
} 
utilizadas pesquisas bibliográficas em livros e artigos de autores ligados aos movimentos sindicais, estudos sociológicos além de entrevistas com lideranças ativas das entidades de representação dos trabalhadores dos Correios no estado do Paraná. O estudo concluiu que entidades sindicais como o SINTCOM-PR são organizações cuja complexidade extrapola, em muito, os arraigados conceitos e estudos sobre os processos de gestão de pessoas em especial nas funções de prospecção e capacitação de lideranças, tornando urgente uma mudança de mentalidade e nos paradigmas que estão vigentes na entidade e suas similares.

Palavras-chave: Atuação Sindical, Reforma Trabalhista, Organização Sindical, Lideranças, identificação.

\section{INTRODUÇÃO}

As mudanças estruturais nas relações de trabalho advindas da Reforma Trabalhista instrumentalizada pela lei no 13.467, de 13 de julho de 2017 causaram o aprofundamento do desequilíbrio de forças entre empregadores e trabalhadores e uma redução significativa do poder de negociação das Entidades Sindicais.

Aprofundando este desequilíbrio, tem-se um contexto político mundial que mostra uma tendência de crescimento de setores conservadores cujo viés ideológico encontrou respaldo no pensamento econômico neoliberal com evidentes impactos sobre as massas de trabalhadores em todo o mundo.

Contribuiu para este crescimento dos setores menos progressistas a frustração das expectativas de avanços sociais criada com a ascensão de governos de esquerda em várias nações, fenômeno observado durante as primeiras décadas do século XXI como o ocorrido no Brasil, com a eleição de Luís Inácio Lula da Silva em 2002.

No Brasil, a estrutura política vigente caracterizada pelo chamado presidencialismo de coalizão, impôs aos governos progressistas a necessidade manutenção de uma base parlamentar sólida que reduziu o ritmo das mudanças necessárias que para a consecução dos seus programas de avanços sociais e impuseram a necessidade de 
negociação de espaços na estrutura da máquina pública através da concessão de cargos para partidos políticos com forte viés fisiológico.

Por outro lado, a pouca maturidade política da população, sua baixa escolaridade, a vigência de quase três décadas de autoritarismo após mais de oitenta anos de alternância de períodos de regimes oligárquicos, populistas e autoritários, onde a participação popular na política foi caracterizada pela pratica do clientelismo, impuseram que a agenda de avanços sociais ocorresse em ritmo mais lento, uma vez que era necessária uma mudança gradual de toda essa estrutura. A tal necessidade, uma vez que não seria aceitável e moralmente defensável a um governo progressista subverter a ordem democrática, podemos atribuir a gradual perda de apoio popular, consequentemente a disseminação nas camadas menos esclarecidas da sociedade em geral de que a esquerda havia aderido ao que se convencionou chamar de "velha política".

Os desgastes decorrentes desse contexto histórico, que impôs a necessidade de negociações, avanços e recuos, bem como a prevalência de forças conservadoras nos meios de comunicação impuseram um desgaste de imagem similar ao sofrido por Getúlio Vargas nos anos 1950 que culminaram com seu suicídio.

Quase tão radical, o golpe jurídico/parlamentar de 2016, foi igualmente traumático, uma vez que após quase 13 anos de governos progressistas, e de quase três anos de desgaste imposto no âmbito do poder legislativo e da mídia, o governo de esquerda foi substituído por uma coalizão de forças conservadoras em um processo de impeachment, que embora previsto no arcabouço jurídico-constitucional vigente, era mortalmente frágil em sua motivação.

A fragilidade jurídica e legal de tal processo e as ligações de seus principais atores com interesses escusos usurparam um mandado legitimamente conquistado nas urnas, para entregá-lo a atores políticos que usualmente agiam nos bastidores do poder em interesse próprio. 
A ausência de lideranças de direita cuja imagem não estivesse ligada a escândalos de corrupção, culminou com o surgimento de uma nova força política, representada por um candidato outsider, cuja biografia pouco conhecida e a ausência de relevância contribuiu para a criação de uma mística de honestidade e independência da estrutura de poder vigente.

Seu discurso radical contra qualquer movimento progressista, o desgaste sistemático do modelo político atual, e a equivocada percepção das lideranças conservadoras de que poderiam tutelar seus arroubos nos trouxeram ao atual momento de total desgaste político e social que estamos vivenciando.

No âmbito dos Movimentos Sindicais, os avanços econômicos e sociais ocorridos no período de 2002 - 2016, turvaram o entendimento do seu necessário papel combativo, visto que a maior parte dos seus dirigentes também eram militantes de esquerda com destacada relevância.

A transição da direita para a esquerda nos anos de 2002/2003 fez necessária a busca de quadros capacitados dos Movimentos Sindicais alinhados com seus programas para ocuparem os espaços no serviço público dominados pelas forças conservadoras.

Transições desta natureza e a necessidade de substituições de postos chaves são naturais em qualquer organização, porém a complexidade aumenta exponencialmente nas empresas públicas, visto que envolve não somente aspectos técnicos, mas principalmente aspectos políticos com impactos não mensuráveis pelos parâmetros empresariais.

O natural processo de migração dos quadros das Lideranças Sindicais para a estrutura formal dos órgãos e empresas estatais, no que se refere à imagem das entidades, trouxe desgastes por ter sido entendida pelos trabalhadores como abandono das causas trabalhistas em proveito próprio. Contribuiu para este entendimento a ausência de participação dos trabalhadores neste processo de indicação, visto que normalmente as decisões nestas entidades são tomadas de forma colegiada, o que não ocorreu neste caso. 
Outra consequência, que será mais profundamente debatida neste artigo, é o fato de que a migração das Lideranças Sindicais mais experientes para a estrutura dos órgãos e empresas públicas ocorreu sem a necessária identificação e atração de novas lideranças nessas entidades, assegurando a continuidade das suas atividades, gerando dessa um vácuo de poder e de gestão.

A máxima política de que "não existe vácuo de poder", citada a exaustão desde a renascença é plenamente aplicável e pôde ser empiricamente comprovada - de forma amarga - neste contexto, visto que esta lacuna de liderança e iniciaram um processo de desmobilização, alienação e distanciamento dos trabalhadores dos Correios com consequências diretas na pouca adesão às lutas pela defesa dos direitos trabalhistas suprimidos em 2020.

\section{CONTEXTUALIZAÇÃO}

A complexidade do tema torna necessário estabelecer como parâmetro de estudo seus efeitos no SINTCOM/PR - Sindicato dos Trabalhadores dos Correios do Paraná - e a decorrente escassez de Lideranças Sindicais capacitadas para atuarem em um contexto de desequilíbrio de forças no campo negocial bem como a necessidade de mecanismos eficientes de a atração, formação e renovação.

Entre 2003 e 2010 os Movimentos Sindicais gozaram de canais comunicação inéditos com o governo, migrando muitas vezes os processos de negociação das bases para as mesas de negociação e esta evolução contribuiu para uma gradual desmobilização dos trabalhadores, visto que foram contemplados em boa parte de suas reivindicações, pois,

A proximidade entre uma parcela do Sindicalismo brasileiro e o governo de Luiz Inácio Lula da Silva, ao invés de fortalecer a capacidade de organização e resistência dos Trabalhadores e de seus organismos de representação, tem evidenciado suas debilidades (GALVÂO, 2012, p. 179). 
A necessária ocupação dos cargos de chefia e direção pelas Lideranças Sindicais trouxeram repercussões negativas à imagem do Movimento Sindical, conforme pode ser observado no que Brandt e Tosta (2008, on-line) descrevem:

Com a regulamentação das centrais Sindicais, o presidente Luiz Inácio Lula da Silva acaba de consagrar seu governo como o que mais benefícios concedeu aos Sindicalistas. Uma pesquisa coordenada por Maria Celina D'Araújo, da Fundação Getúlio Vargas, indica que 45\% dos cargos de alto comando dentro do governo estão hoje nas mãos de sindicalizados enquanto a média nacional é de apenas $14 \%$.

No âmbito dos Correios temos como exemplo dessa apropriação de quadros a escolha de uma das mais proeminentes Lideranças Sindicais como para Diretor Regional da Superintendência Estadual de Operações do Paraná, sem que ocorressem ações no âmbito da Entidade para suprimir essa lacuna de capital intelectual como ocorrem em organizações privadas. Longe de ser um caso isolado, perdas como essa ocorram de forma generalizada nos níveis mais elementares até os mais elevados de postos gerenciais.

Efeito secundário dessa disputa de recursos humanos qualificados foi o surgimento de um ambiente propício para ataques a credibilidade das Entidades de representação dos Trabalhadores dos Correios, que alijados do processo decisório dessas escolhas, tornaram-se presas fáceis dessa manipulação.

Por outro lado, não se pode olvidar que no período iniciado em 1ํ de janeiro de 2003 quando a condução do país esteve a cargo de forças progressistas, observou-se um protagonismo inédito dos Movimentos Sociais e de acentuado crescimento econômico.

Quadro 1 - Recomposição Salarial - Correios 2003/2010

RECOMPOSIÇÃO SALARIAL GOVERNO LULA (2003-2010)

\begin{tabular}{|l|l|l|}
\hline ANO & $\%$ ACT & \% IPCA \\
\hline 2003 & $22,72 \%$ & $9,30 \%$ \\
\hline 2004 & $12,15 \%$ & $7,60 \%$ \\
\hline
\end{tabular}




\begin{tabular}{|l|l|l|}
\hline 2005 & $12,43 \%$ & $5,69 \%$ \\
\hline 2006 & $9,18 \%$ & $3,14 \%$ \\
\hline 2007 & $3,74 \%$ & $4,46 \%$ \\
\hline 2008 & $16,21 \%$ & $5,90 \%$ \\
\hline 2009 & $20,81 \%$ & $4,31 \%$ \\
\hline 2010 & $1,00 \%$ & $5,91 \%$ \\
\hline ACUMULADO & $\mathbf{1 4 8 , 5 2} \%$ & $\mathbf{5 6 , 6 8 \%}$ \\
\hline
\end{tabular}

Fonte: Elaborado pelo autor (2020).

O quadro acima, lista apenas a recomposição das perdas salariais dos Trabalhadores dos Correios ocorridas durante os governos anteriores, em especial no período 1994/2002, e não contempla os avanços obtidos em seus benefícios como a concessão de adicionais por atividades a exemplo dos Carteiros que foram contemplados com um adicional de $30 \%$ sobre seus vencimentos base.

Embora em menor ritmo, essa tendência de recomposição das perdas salariais continuou no período do governo Dilma Rousseff conforme pode ser observado no quadro abaixo:

Quadro 2 - Recomposição Salarial - Correios 2011/2016

\begin{tabular}{|l|l|l|}
\hline \multicolumn{3}{|l|}{ RECOMPOSIÇÃO SALARIAL GOVERNO DILMA (2011-2016) } \\
\hline ANO & $\%$ ACT & \% IPCA \\
\hline 2011 & $14,37 \%$ & $9,30 \%$ \\
\hline 2012 & $6,50 \%$ & $7,60 \%$ \\
\hline 2013 & $8,00 \%$ & $5,69 \%$ \\
\hline 2014 & $0,00 \%$ & $3,14 \%$ \\
\hline 2015 & $9,96 \%$ & $4,46 \%$ \\
\hline 2016 & $21,73 \%$ & $5,90 \%$ \\
\hline ACUMULADO & $\mathbf{7 6 , 0 8 \%}$ & $\mathbf{4 1 , 8 2 \%}$ \\
\hline
\end{tabular}

Fonte: Elaborado pelo autor (2020). 
Os números acima contrastam de forma gritante com os números das negociações coletivas ocorridas nos anos subsequentes após o golpe jurídico/parlamentar contra a Presidenta Dilma Rousseff em 2016, no mandato de Michel Temer Lulia e nos dois primeiros anos de governo de Jair Messias Bolsonaro.

Quadro 3 - Perdas Salariais - Correios 2017/2020*

\begin{tabular}{|l|l|l|}
\hline \multicolumn{4}{|l|}{ PERDAS SALARIAIS GOVERNOS } & $(2017-2020)$ \\
\hline ANO & $\%$ ACT & $\%$ IPCA \\
\hline 2017 & $2,07 \%$ & $9,30 \%$ \\
\hline 2018 & $3,61 \%$ & $7,60 \%$ \\
\hline 2019 & $3,00 \%$ & $5,69 \%$ \\
\hline 2020 & $2,60 \%{ }^{*}$ & $40,00^{* *}$ \\
\hline ACUMULADO & $\mathbf{1 1 , 7 6 \%}$ & $\mathbf{7 9 , 4 1 \%}$ \\
\hline
\end{tabular}

Fonte: Elaborado pelo autor (2020).

*Sentença ACT 020 (RODRIGUES, 2020).

** Projeção IPCA e perda média de benefícios cortados (RODRIGUES, 2020).

Além das perdas inflacionárias que corroeram a recomposição salarial implementada nos governos de esquerda e o poder de compra dos benefícios, ocorreu também a imposição de pesadas mensalidades no plano de saúde dos trabalhadores e seus percentuais de compartilhamento, comprometendo grande parte dos rendimentos dos Trabalhadores, em especial os de menor faixa salarial.

Por fim, em 21 de setembro de 2020, ocorreu uma drástica redução de rendimentos com cortes de benefícios e direitos históricos dos trabalhadores no julgamento do dissídio do ACT - Acordo Coletivo de Trabalho 2020/2021. Tais cortes objetivam a redução dos custos da mão de obra empregada nos Correios, tornando a empresa ainda mais atrativa para o mercado logístico, visto o governo federal manifestou explicitamente o desejo de venda da Estatal. 


\section{PROBLEMÁTICA}

O período iniciado em 2003 foi caracterizado por uma harmonia relativa entre os Trabalhadores e as sucessivas direções os Correios, porém, a insatisfação com a velocidade das mudanças decorrentes de uma demanda reprimida por avanços sociais levou a um tensionamento das relações Sindicais e o governo.

O natural alinhamento entre as Entidades Sindicais dos Trabalhadores dos Correios, uma empresa pública, cujo único acionista é o governo federal, que conforme visto foi capitaneado por governos progressistas, turvou o entendimento de suas Lideranças sobre o seu papel necessariamente combativo, conforme se observa no depoimento de Filho (2014, apud RATO; MASSUELLA; VERONESI, 2014, on-line), da CSP Conlutas:

Quando entrou o governo Lula e depois o de Dilma, as centrais ficaram do lado do governo. Um reflexo disso são as greves. Depois que o PT assumiu, essas manifestações diminuíram. Quando era no governo do Fernando Henrique Cardoso, eles se manifestavam muito mais.

Essa percepção pode ser explicada pela falsa ideia de que uma luta Sindical mais aguerrida sabotaria um projeto maior de avanços sociais, além da já citada incompreensão da necessidade de buscar nos quadros do Movimento Sindical para ocuparem funções gerenciais na máquina pública, privando essas Entidade de Lideranças experientes.

Este rearranjo, a despeito de seus efeitos negativos, funcionou bem até o ano de 2016, e conforme já demonstrado, a despeito das frustrações com a velocidade dos avanços das conquistas trabalhistas, trouxe substanciais vantagens econômicas para os Trabalhadores dos Correios.

Com transição do governo Lula para a sua sucessora Presidente Dilma Vana Rousseff em 01 de janeiro de 2011, observou-se uma redução do acesso das Entidades Sindicais aos mais altos escalões de poder, o que seria uma situação natural de distanciamento, foi erroneamente interpretado como piora nas relações entre Entidades Sindicais e o governo, atribuindo a então mandatária um perfil "menos 
acessível", conforme pode ser observado no depoimento do líder da força Lino Almeida (2014 apud RATO; MASSUELA; VERONESI, 2014, on-line), "com o Lula [2003-2010] nós tínhamos mais força no governo. Tínhamos um acesso maior a esses assuntos, mas a Dilma [Rousseff] acabou com essas conversas. Ela toma decisões mais individuais, não conversa com os sindicatos."

Esse suposto distanciamento, decorreu da adoção de uma postura natural de observação da "liturgia do cargo" ocupado, e conforme observa-se hoje não pode caracterizou o abandono da classe trabalhadora (vide quadro 2) ao contrário, tal interlocução foi acertadamente delegada a interlocutores experientes, sendo interrompida em decorrência da sistemática oposição sofrida durante seus mandatos que culminaram com seu o emparedamento e posterior impeachment em 31 agosto de 2016.

Ao final deste processo de combate às forças progressistas que está em pleno curso, restou aos sindicatos um cenário de "terra arrasada" decorrente da perda de lideranças, capital intelectual, planejamento, organização administrativa e financeira, incapacidade de atrair potenciais lideranças decorrentes da contaminação de trabalhadores através do massacre de informações tendenciosas de todo aparato midiático criado para favorecer o golpe de 31 de agosto de 2016 e a eleição de um governo de extrema direita em 2018.

A fonte natural de atração de lideranças, as unidades operacionais dos Correios, chamado "chão de fábrica" foi também submetido a uma enxurrada de noticias falsas e de desinformação. Carente de uma formação política sólida e inebriados pelas conquistas econômicas propiciadas pelos governos progressistas, assumiram uma identidade e autoimagem descolada da realidade, tomando para si valores altamente conservadores e contrários aos próprios interesses.

Paradoxalmente o efeito psicológico do acentuado aumento da renda propiciado pela política de inclusão da esquerda foi justamente o surgimento da sensação de pertencimento à chamada "classe média" por parte daqueles que até o final do ano de 2002 estavam na base da pirâmide social. 
A política de inclusão dos trabalhadores em um ambiente de consumo em que sempre estiveram a margem, sem uma necessária formação política, também teve como efeito secundário o fenômeno da adoção de uma visão de mundo excludente, como brilhantemente apontou Souza (2019) ao analisar a adesão da classe trabalhadora a valores tão contrários aos seus interesses:

Hoje em dia, o capitalismo financeiro começa a criar sua própria classe trabalhadora crescentemente precarizada e ameaçada pelo desemprego e por cortes de direitos. Pior ainda. Parte dela se identifica com os opressores e se imagina "empresária de si mesma". A competição tende a superar a solidariedade de classe como efeito de vários fatores. A conquista dessa nova classe trabalhadora precarizada - que um marketing míope e pouco inteligente do próprio PT chamou de "nova classe média" - será o principal desafio para qualquer perspectiva crítica no espectro político do futuro (SOUZA, 2019, p. 115).

No âmbito do SINTCOM-PR, as diretorias eleitas nos triênios 2015/2017 e 2017/2019 foram afetadas por este cenário de indefinição sobre o papel dos Sindicatos, e em um contexto totalmente novo e desfavorável, tronaram-se alvo atrativo para as novas Centrais Sindicais surgidas na esteira da insatisfação com os rumos adotados: a CONLUTAS e a InterSindical,

A Frente de Esquerda Socialista (FES), por sua vez, cujos principais dirigentes são ligados ao PSOL, criou a InterSindical por entender que a central deixou de ser um instrumento de organização e unificação do movimento Sindical para ser um instrumento de colaboração e conciliação de classes. Porém, nem todos os dirigentes e Sindicatos que a integram deixaram a central, optando por um duplo movimento: ao mesmo tempo em que avaliam que a resistência e o enfrentamento no interior da CUT não são mais suficientes, entendem que é preciso reconhecer a legitimidade daqueles que continuam lutando dessa forma (GALVÃO, 2009, p. 187).

A entrada destes novos atores no cenário do Movimento Sindical no Paraná, longe de redirecionar seus rumos, mostrou-se um fator de desmobilização, visto que esses novos agentes, em boas partes inexperientes, imaturos, excessivamente tutelados a correntes radicais, e desprovidos de conhecimentos administrativos, acabaram por empurrar o Sindicato em um abismo financeiro e projetando uma imagem que gerou ao descrédito junto aos trabalhadores. 
Em abril de 2019, com a eleição da nova diretoria, em um contexto de sucessivas supressões de direitos trabalhistas promovidos por um governo de extrema direita empossado em 01 de janeiro do mesmo ano, o SINTCOM-PR viu-se desafiado a reconstruir sua credibilidade junto aos trabalhadores com um grupo de 35 diretores dos quais mais de $75 \%$ com pouca ou nenhuma experiência Sindical, cuja visão política necessita de aprimoramento através de um consistente processo de formação nessa área.

Considerando o fato de que diferentemente de organizações clássicas onde seus quadros são selecionados dentro de parâmetros pré-estabelecidos e compromissos com as suas visões, nas Entidades Sindicais, suas Lideranças são eleitas, e traduzem as expectativas dos seus representados, mesmo que essas expectativas colidam com os valores que norteiam a luta Sindical ou com os próprios interesses dos representados.

Com presente artigo pretendemos propor alternativas que supram as lacunas de formação necessárias para que estes dirigentes atuem de forma eficiente em suas atribuições, dentro das premissas esperadas para os que representam os interesses da classe trabalhadora e assegurando que o processo de formação e construção do conhecimento amplo seja incorporado ao movimento Sindical.

\section{UNIVERSO DE SELEÇÃO E ESTRATÉGIAS DE PROSPECÇÃO DE LIDERANÇAS}

Em decorrência da ruptura ocorrida no quinquênio 2015/2020, da ausência de planejamento, de estratégias de médio e longo prazo e do despreparo para lidar com um cenário para o qual não se vislumbrava a ocorrência, inexiste uma base sólida de conhecimentos a partir da qual possa ser construída uma estratégia de atração lideranças capazes de atuar de forma eficaz e alinhada aos valores da organização.

Enfrenta-se hoje o desafio adicional de lidar com Diretores e Delegados Sindicais que não assimilaram seu papel na organização e a responsabilidade de liderar pessoas 
em situações de enfretamento ou mesmo habilidades de negociação que agreguem trabalhadores em torno de uma causa comum.

Estabelecido que diferentemente de organizações clássicas, a prospecção consideramos mais apropriado o termo atração - de potenciais lideranças está em sua maior parte condicionada a fatores externos e contextos que limitam suas ações, consequentemente o foco das entidades deve ser direcionado a formação do material humano disponível, possibilitando sua atuação como multiplicadores em suas bases, influindo a médio e longo prazo nos processos de escolha, adequando o capital humano aos seus valores.

Esses limitadores, e por que não dizer barreiras, impõe a necessidade de um trabalho consistente de formação alinhado com os valores da organização e com os atributos necessários para sua realização.

\subsection{COMPETÊNCIAS DESEJADAS E SEU DESENVOLVIMENTO}

Não se pode pretender uma abordagem diferente do conceito de Competências desejadas às Lideranças Sindicais dos conceitos estabelecidos desde o início dos seus estudos após a revolução industrial, cuja síntese de Fleury e Fleury (2001, p. 185) resume como sendo "um conjunto de conhecimentos, habilidades e atitudes que justificam um alto desempenho, acreditando-se que os melhores desempenhos estão fundamentados na inteligência e personalidade das pessoas".

Embora essa abordagem das competências seja aparentemente fática por qualificálas como qualidades pré-existentes, omitindo o fato de que através de ações de formação possam vir a ser desenvolvidas, incentivadas e aprimoradas, ela deixa claro que a Sindicato deve atrair recursos humanos que apresentem um conjunto maior possível desses atributos. E qual seriam esses?

Considerando as atividades das Entidades Sindicais pode-se com certo grau de segurança listar um rol de competências essenciais bastante uniforme conforme o quadro 4 abaixo e o quadro 5, na subseção 4.3: 
Quadro 4 - Competências Essenciais - Atividade Sindical - SINTCOM-PR

\begin{tabular}{|c|c|c|}
\hline EIXO & COMPETÊNCIA & $\begin{array}{l}\text { DESCRIÇÃO (O quê, } \\
\text { Como, Para quê) }\end{array}$ \\
\hline COMUNICAÇÃO & $\begin{array}{l}\text { PLANEJAMENTO DE } \\
\text { COMUNICAÇÃO }\end{array}$ & $\begin{array}{l}\text { Capacidade de comunicar- } \\
\text { se de forma clara e } \\
\text { assertiva com diversos } \\
\text { públicos, utilizando } \\
\text { habilidades pessoais e } \\
\text { técnicas de comunicação, } \\
\text { influência e persuasão, } \\
\text { para atingir objetivos e } \\
\text { metas do Sindicato e para } \\
\text { criar e manter redes de } \\
\text { relacionamento. } \\
\text { Capacidade de entender } \\
\text { as necessidades da } \\
\text { Entidade em diversos } \\
\text { momentos e adequar-se a } \\
\text { estas, definindo diretrizes } \\
\text { de sua estratégia de } \\
\text { comunicação, } \\
\text { considerando os objetivos } \\
\text { estratégicos do Sindicato e } \\
\text { as ferramentas disponíveis } \\
\text { no momento, tendo como } \\
\text { finalidade o fortalecimento } \\
\text { da fortalecer a imagem e o } \\
\text { relacionamento } \\
\text { Sindicato com partes } \\
\text { interessadas. }\end{array}$ \\
\hline
\end{tabular}




\begin{tabular}{|c|c|c|}
\hline \multirow[t]{3}{*}{ GESTÃO DAS ATIVIDADES } & $\begin{array}{l}\text { ANÁLISE } \\
\text { CENÁRIOS }\end{array}$ & $\begin{array}{l}\text { Capacidade de analisar } \\
\text { informações relativas a } \\
\text { tendências } \\
\text { Movimentos dos } \\
\text { identificando possíveis } \\
\text { ameaças e oportunidades, } \\
\text { para definir estratégias } \\
\text { eficazes de atuação do } \\
\text { Sindicato. }\end{array}$ \\
\hline & $\begin{array}{l}\text { FOCO NAS } \\
\text { MELHORES } \\
\text { PRÁTICAS }\end{array}$ & $\begin{array}{l}\text { Capacidade de identificar } \\
\text { e estimular a adoção das } \\
\text { melhores práticas por } \\
\text { parte dos representantes e } \\
\text { Trabalhadores, através de } \\
\text { pesquisas, trocas de } \\
\text { experiências, } \\
\text { compartilhamento de } \\
\text { conhecimentos, } \\
\text { possibilitando } \\
\text { aprimoramento da gestão } \\
\text { administrativa e das } \\
\text { atividades de mobilização, } \\
\text { com o foco no aumento da } \\
\text { representatividade do } \\
\text { Sindicato. }\end{array}$ \\
\hline & INOVAÇÃO SINDICAL & $\begin{array}{l}\text { Capacidade de direcionar } \\
\text { seus esforços para uma } \\
\text { atuação inovadora, } \\
\text { através da identificação de } \\
\text { oportunidades de } \\
\text { melhorias nos "processos }\end{array}$ \\
\hline
\end{tabular}




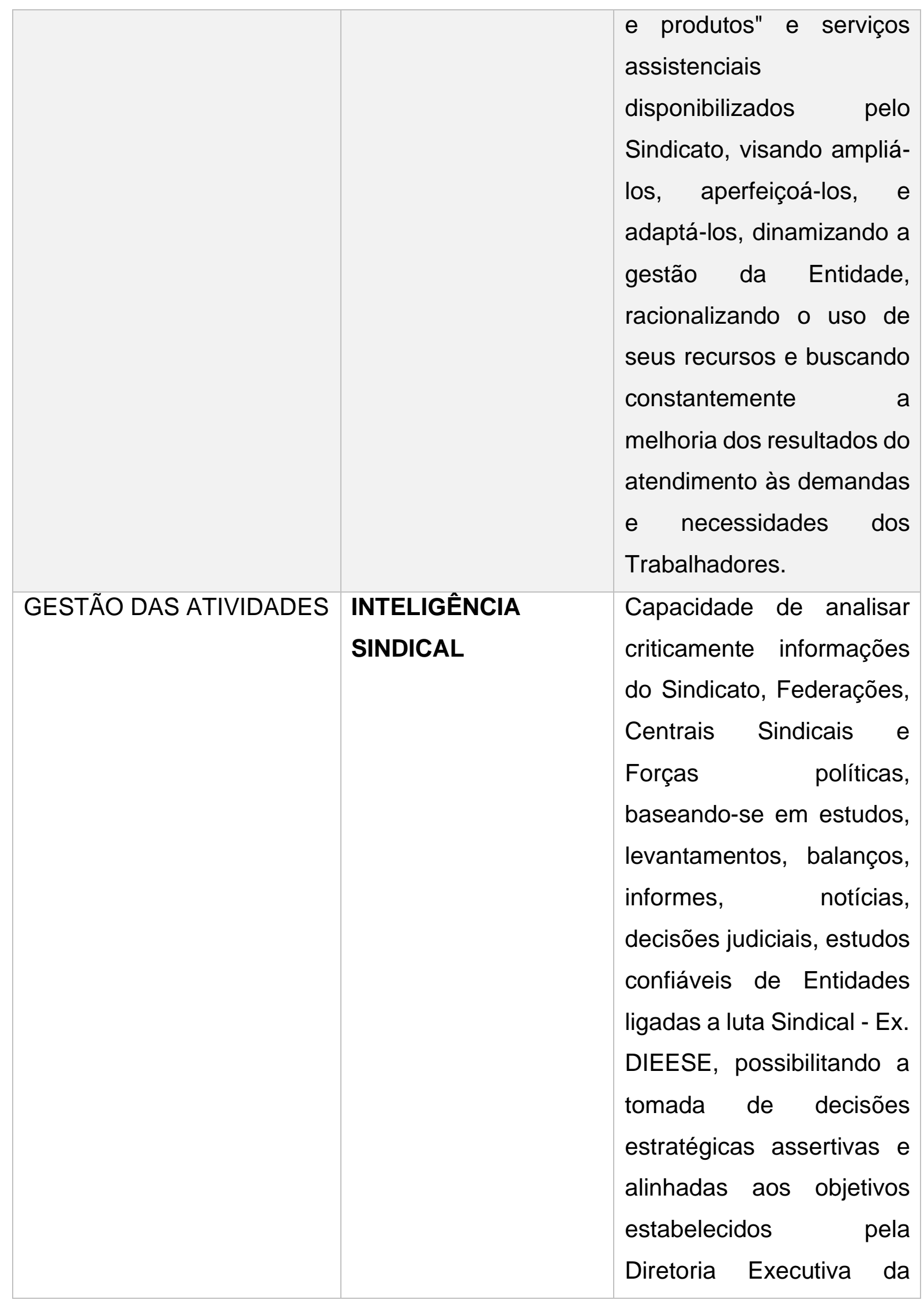




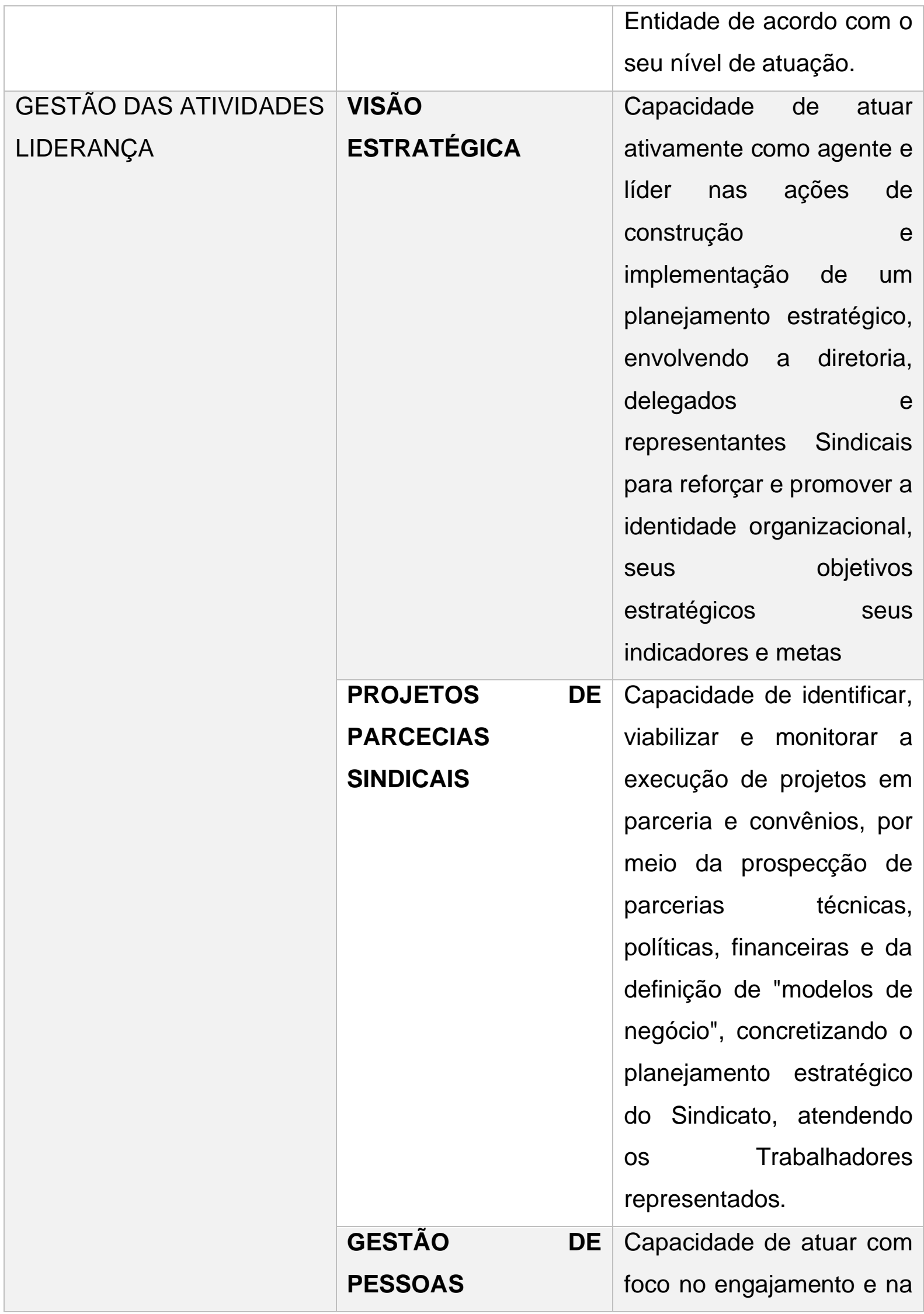




\begin{tabular}{|c|c|c|}
\hline & & $\begin{array}{l}\text { sua } \\
\text { (desempenho) na luta } \\
\text { Sindical, } \\
\text { Delegados, } \\
\text { Representantes } \\
\text { Trabalhadores), através } \\
\text { de ações de sensibilização } \\
\text { e desenvolvimento de } \\
\text { competências, garantindo } \\
\text { o alcance dos objetivos } \\
\text { estratégicos do Sindicato. }\end{array}$ \\
\hline \multirow{3}{*}{$\begin{array}{l}\text { LIDERANÇA } \\
\text { RELACIONAMENTO }\end{array}$} & LIDERANÇA & Capacidade de sensibilizar \\
\hline & AGREGADORA & $\begin{array}{l}\text { e mobilizar os } \\
\text { Trabalhadores, } \\
\text { disseminando as ações } \\
\text { coletivas bem-sucedidas, } \\
\text { promovendo a imagem de } \\
\text { confiança, solidez e } \\
\text { propósito do Sindicato, } \\
\text { possibilitando um } \\
\text { ambiente favorável ao seu } \\
\text { fortalecimento através da } \\
\text { adesão de todos os } \\
\text { Trabalhadores. }\end{array}$ \\
\hline & $\begin{array}{l}\text { ATUAÇÃO } \\
\text { CONSULTIVA }\end{array}$ & $\begin{array}{l}\text { Capacidade de atuar de } \\
\text { forma consultiva no } \\
\text { atendimento às demandas } \\
\text { dos Trabalhadores, } \\
\text { através da utilização dos } \\
\text { conhecimentos das } \\
\text { normas internas dos }\end{array}$ \\
\hline
\end{tabular}




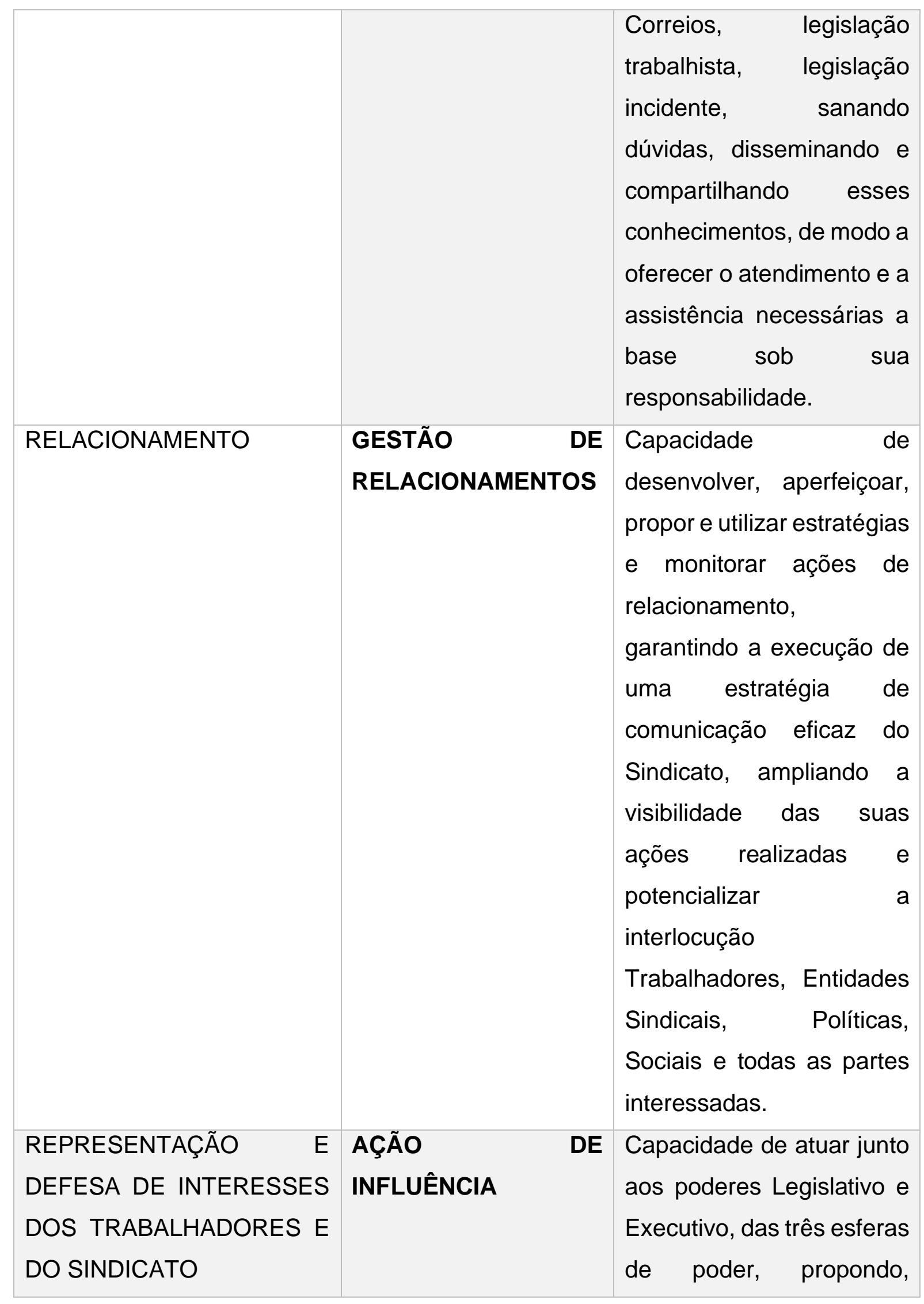




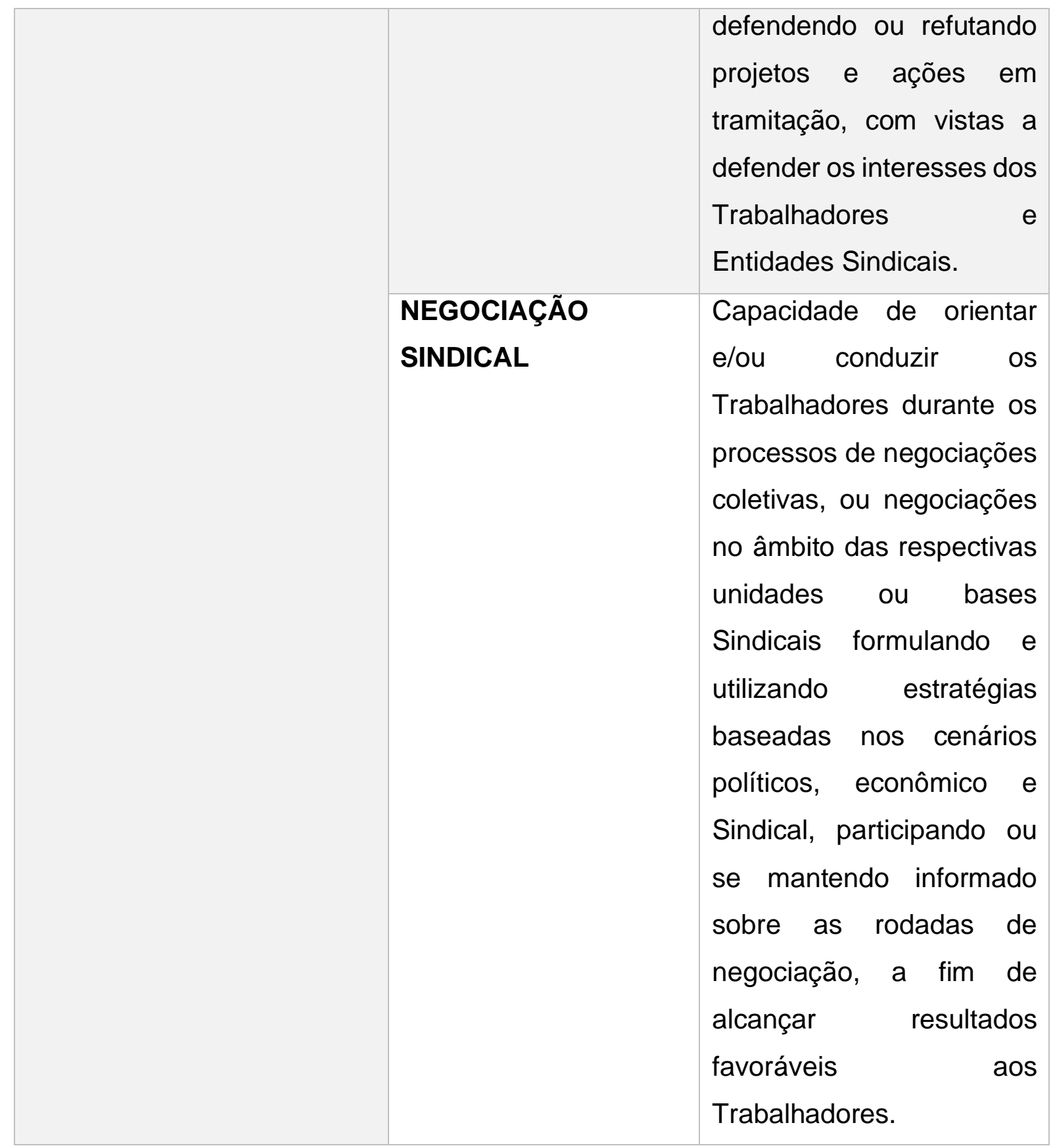

Fonte: Elaborado pelo autor (2020).

Considerando as Competências desejáveis e acima listadas, as limitações da função atração decorrentes da natureza da Entidade Sindical, tem-se como estratégia para a obtenção de quadros capacitados o direcionamento dos recursos e esforços no processo básico de desenvolvimento de pessoas, através de uma política consistente de treinamentos cujas necessidades devem ser mapeadas (CHIAVENATO, 2015). 


\subsection{NECESSIDADES DE TREINAMENTO}

O conceito clássico de que o treinamento se limita a uma ferramenta de adequação das pessoas ao seu cargo com o objetivo de desenvolvê-las simplesmente para melhorar o desempenho no cargo, além de ultrapassado, é inadequado às entidades cuja natureza está diretamente ligada a defesa valores e interesses de trabalhadores e a atuação em conjunto com diversos agentes sociais, ou seja, valores intangíveis e em sua maioria não passiveis de mensuração (CHIAVENATO, 2015).

Não o bastante, a partir da premissa de que os treinamentos são meios de desenvolvimento de competências para que as pessoas se tornem mais produtivas, criativas e inovadoras a fim de contribuir melhor para os objetivos organizacionais e se tornar cada vez mais valiosas (CHIAVENATO, 2015).

Em um contexto de desequilíbrio de forças entre empregadores e Trabalhadores, contaminação dos poderes executivo, legislativo, judiciário, da opinião pública e sociedade em geral contra os Sindicatos e Trabalhadores, em especial das empresar públicas, tornou premente a necessidade de que as ações de treinamento tenham como foco a formação político-sindical das novas lideranças do Sindicato dos Trabalhadores dos Correios do Paraná.

Não menos importante observa-se que a maior parte dos Diretores e Delegados eleitos do SINTCOM-PR, a despeito de suas experiências práticas nas atividades Sindicais, não dispõe de conhecimentos de ferramentas básicas para assegurar que esses conhecimentos sejam sistematizados e consolidado em registros que permitam sua consulta e até mesmo que se transformem em conhecimento (além do oral).

Spector (2012) estabelece que a definição de objetivos é um dos passos mais importantes do desenvolvimento de um programa de treinamento, e a clareza desses objetivos é determinante para seu sucesso, cujos critérios e devem incluir o que o treinando deveria ser capaz de fazer ou saber após o treinamento. 
Dentro dessa definição, que consideramos bastante apropriada, podemos listar os objetivos a serem atingidos pelo SINTCOM-PR no que tange ao treinamento e desenvolvimento de suas Lideranças em ciclos anuais.

\subsection{OBJETIVOS DAS AÇÕES DE TREINAMENTO}

Com base nas competências necessárias para a atuação das Lideranças Sindicais, combinadas com as necessidades de treinamento identificadas, considerando ainda o contexto de estrangulamento financeiro e de redução do número de Dirigentes Sindicais ocorrido após o julgamento do dissídio coletivo dos trabalhadores dos Correios, no Acordo Coletivo de Trabalho de 2020/2021, podemos listar com bastante segurança um rol de treinamentos que podem reduzir ou até mesmo suprir as demandas necessárias. Longe de ser definitivo, esse rol, serve de norte para um planejamento que deve ser dinâmico e sistematicamente atualizado.

Por outro lado, considerando a natureza das atividades sindicais, é extremamente complexa e subjetiva a mensuração dos resultados destas ações, impondo a Diretoria Executiva da Entidade a tarefa de verificar a necessidade de adequações ao longo do ciclo anual proposto.

Quadro 5 - Ações de Treinamento - Atividade Sindical - SINTCOM-PR

\begin{tabular}{|c|c|c|c|c|}
\hline $\begin{array}{l}\text { COMPETÊNCIA } \\
\text { ALVO }\end{array}$ & OBJETIVO & $\begin{array}{l}\text { AÇÃO DE } \\
\text { TREINAMENT } \\
\text { O }\end{array}$ & INSTITUIÇÃO & MODAL \\
\hline COMUNICAÇÃO & $\begin{array}{l}\text { Desenvolver } \\
\text { a capacidade } \\
\text { de } \\
\text { comunicar-se } \\
\text { de forma } \\
\text { clara e }\end{array}$ & $\begin{array}{l}\text { Formação } \\
\text { Política } \\
\text { Sindical }\end{array}$ & $\begin{array}{l}\text { ILAESE - } \\
\text { Instituto Latino } \\
\text { Americano de } \\
\text { Estudos } \\
\text { Socioeconômic } \\
\text { os. }\end{array}$ & $\begin{array}{l}\text { Presenci } \\
\text { al }\end{array}$ \\
\hline
\end{tabular}




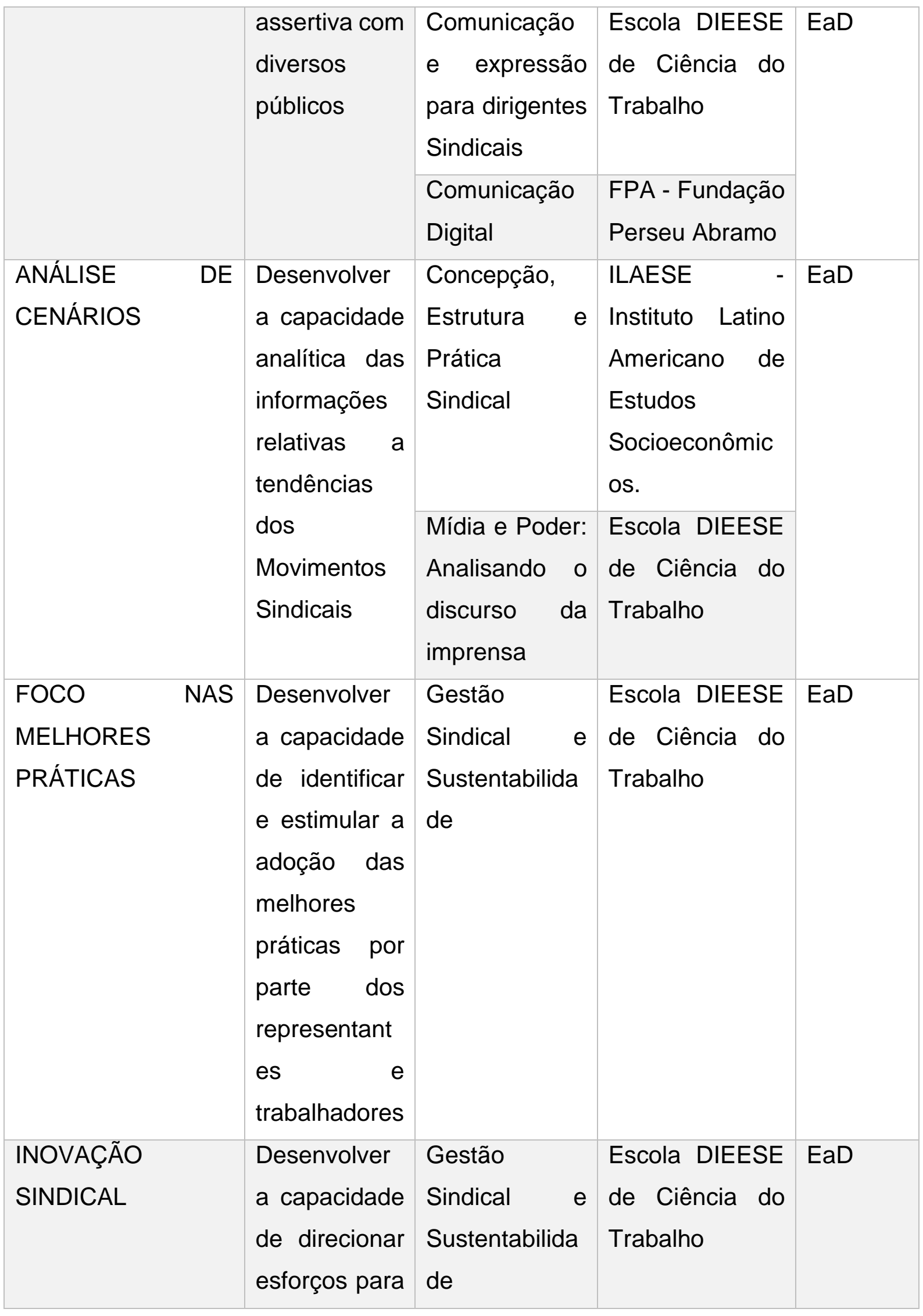




\begin{tabular}{|c|c|c|c|c|}
\hline & $\begin{array}{l}\text { uma atuação } \\
\text { inovadora. }\end{array}$ & & & \\
\hline $\begin{array}{l}\text { INTELIGÊNCIA } \\
\text { SINDICAL }\end{array}$ & $\begin{array}{l}\text { Desenvolver } \\
\text { a capacidade } \\
\text { de analisar } \\
\text { criticamente } \\
\text { informações. }\end{array}$ & $\begin{array}{l}\text { Formação } \\
\text { Política } \\
\text { Sindical }\end{array}$ & $\begin{array}{l}\text { ILAESE - } \\
\text { Instituto Latino } \\
\text { Americano de } \\
\text { Estudos } \\
\text { Socioeconômic } \\
\text { os. }\end{array}$ & $\begin{array}{l}\text { Presenci } \\
\text { al }\end{array}$ \\
\hline $\begin{array}{l}\text { VISÃO } \\
\text { ESTRATÉGICA }\end{array}$ & $\begin{array}{l}\text { Desenvolver } \\
\text { a capacidade } \\
\text { de atuar } \\
\text { ativamente } \\
\text { como agente } \\
\text { e líder nas } \\
\text { ações de } \\
\text { construção e } \\
\text { implementaç } \\
\text { ão de } \\
\text { planejamento } \\
\text { estratégico. }\end{array}$ & $\begin{array}{l}\text { Gestão } \\
\text { Sindical e } \\
\text { Sustentabilida } \\
\text { de }\end{array}$ & $\begin{array}{l}\text { Escola DIEESE } \\
\text { de Ciência do } \\
\text { Trabalho }\end{array}$ & $\mathrm{EaD}$ \\
\hline $\begin{array}{l}\text { PROJETOS DE } \\
\text { PARCECIAS } \\
\text { SINDICAIS }\end{array}$ & $\begin{array}{l}\text { Desenvolver } \\
\text { a capacidade } \\
\text { de identificar, } \\
\text { viabilizar e } \\
\text { monitorar a } \\
\text { execução de } \\
\text { projetos em } \\
\text { parceria e } \\
\text { convênios. }\end{array}$ & $\begin{array}{l}\text { Gestão } \\
\text { Sindical e } \\
\text { Sustentabilida } \\
\text { de }\end{array}$ & $\begin{array}{l}\text { Escola DIEESE } \\
\text { de Ciência do } \\
\text { Trabalho }\end{array}$ & $\mathrm{EaD}$ \\
\hline
\end{tabular}




\begin{tabular}{|c|c|c|c|c|}
\hline $\begin{array}{l}\text { GESTÃO } \\
\text { PESSOAS }\end{array}$ & $\begin{array}{l}\text { Desenvolver } \\
\text { a capacidade } \\
\text { de atuar com } \\
\text { foco no } \\
\text { engajamento } \\
\text { na luta } \\
\text { Sindical da } \\
\text { Diretoria, }\end{array}$ & $\begin{array}{l}\text { Formação } \\
\text { Política } \\
\text { Sindical }\end{array}$ & $\begin{array}{l}\text { ILAESE - } \\
\text { Instituto Latino } \\
\text { Americano de } \\
\text { Estudos } \\
\text { Socioeconômic } \\
\text { os. }\end{array}$ & $\begin{array}{l}\text { Presenci } \\
\text { al }\end{array}$ \\
\hline $\begin{array}{l}\text { LIDERANÇA } \\
\text { AGREGADORA }\end{array}$ & $\begin{array}{l}\text { Desenvolver } \\
\text { a capacidade } \\
\text { de } \\
\text { sensibilizar e } \\
\text { mobilizar os } \\
\text { Trabalhadore } \\
\text { s. }\end{array}$ & $\begin{array}{l}\text { Formação } \\
\text { Política } \\
\text { Sindical }\end{array}$ & $\begin{array}{l}\text { ILAESE - } \\
\text { Instituto Latino } \\
\text { Americano de } \\
\text { Estudos } \\
\text { Socioeconômic } \\
\text { os. }\end{array}$ & $\begin{array}{l}\text { Presenci } \\
\text { al }\end{array}$ \\
\hline $\begin{array}{l}\text { ATUAÇÃO } \\
\text { CONSULTIVA }\end{array}$ & $\begin{array}{l}\text { Desenvolver } \\
\text { a capacidade } \\
\text { de atuar de } \\
\text { forma } \\
\text { consultiva no } \\
\text { atendimento } \\
\text { às demandas } \\
\text { dos } \\
\text { Trabalhadore } \\
\text { s. }\end{array}$ & $\begin{array}{lr}\text { Pesquisa } & \text { e } \\
\text { utilização } & \text { dos } \\
\text { Sistemas } & \text { de } \\
\text { Gestão dos } \\
\text { Correios. }\end{array}$ & $\begin{array}{l}\text { SINTCOM/PR } \\
\text { Sindicato dos } \\
\text { Trabalhadores } \\
\text { dos Correios do } \\
\text { Paraná }\end{array}$ & $\begin{array}{l}\text { Presenci } \\
\text { al }\end{array}$ \\
\hline $\begin{array}{l}\text { GESTÃO DE } \\
\text { RELACIONAMENT } \\
\text { OS }\end{array}$ & $\begin{array}{l}\text { Desenvolver } \\
\text { a capacidade } \\
\text { de criar, } \\
\text { aperfeiçoar, } \\
\text { propor e } \\
\text { utilizar }\end{array}$ & $\begin{array}{l}\text { Formação } \\
\text { Política } \\
\text { Sindical }\end{array}$ & $\begin{array}{l}\text { ILAESE - } \\
\text { Instituto Latino } \\
\text { Americano de } \\
\text { Estudos } \\
\text { Socioeconômic } \\
\text { os. }\end{array}$ & $\begin{array}{l}\text { Presenci } \\
\text { al }\end{array}$ \\
\hline
\end{tabular}




\begin{tabular}{|c|c|c|c|c|}
\hline & $\begin{array}{l}\text { estratégias e } \\
\text { monitorar } \\
\text { ações de } \\
\text { relacionamen } \\
\text { to }\end{array}$ & & & \\
\hline $\begin{array}{ll}\text { AÇÃO } & \text { DE } \\
\text { INFLUÊNCIA } & \end{array}$ & $\begin{array}{l}\text { Desenvolver } \\
\text { a capacidade } \\
\text { de atuar junto } \\
\text { aos poderes } \\
\text { Legislativo e } \\
\text { Executivo, } \\
\text { das três } \\
\text { esferas de } \\
\text { poder. }\end{array}$ & $\begin{array}{l}\text { Estado e } \\
\text { Processo } \\
\text { Legislativo }\end{array}$ & $\begin{array}{l}\text { Escola DIEESE } \\
\text { de Ciência do } \\
\text { Trabalho. }\end{array}$ & $\mathrm{EaD}$ \\
\hline \multirow[t]{2}{*}{$\begin{array}{l}\text { NEGOCIAÇÃO } \\
\text { SINDICAL }\end{array}$} & $\begin{array}{l}\text { Desenvolver } \\
\text { a capacidade } \\
\text { de orientar } \\
\text { e/ou conduzir } \\
\text { os } \\
\text { Trabalhadore }\end{array}$ & $\begin{array}{l}\text { Formação } \\
\text { Política } \\
\text { Sindical }\end{array}$ & $\begin{array}{l}\text { ILAESE - } \\
\text { Instituto Latino } \\
\text { Americano de } \\
\text { Estudos } \\
\text { Socioeconômic } \\
\text { os. }\end{array}$ & $\begin{array}{l}\text { Presenci } \\
\text { al }\end{array}$ \\
\hline & $\begin{array}{l}\text { s durante os } \\
\text { processos de } \\
\text { negociações. }\end{array}$ & $\begin{array}{l}\text { Técnicas de } \\
\text { Negociação }\end{array}$ & $\begin{array}{l}\text { Escola DIEESE } \\
\text { de Ciência do } \\
\text { Trabalho }\end{array}$ & $\mathrm{EaD}$ \\
\hline
\end{tabular}

Fonte: Elaborado pelo autor (2020).

\section{CONCLUSÃO}

Entidades como o Sindicato dos Trabalhadores dos Correios do Paraná, são organizações cuja complexidade extrapola em muito os arraigados conceitos e estudos sobre os Processos de Gestão, em especial os de agregar e desenvolver pessoas. 
Ademais, em grande parte das entidades dessa natureza, há grande resistência a adoção de modelos de gestão que remetam a similaridades com organizações clássicas, vistas não sem alguma razão, como exploradoras da mão de obra de seus recursos humanos.

Entretanto, há uma urgência na mudança dessa mentalidade e nos paradigmas que dominam estas entidades, e em face do atual cenário, em especial para os trabalhadores dos Correios, cujas perdas e supressões de diretos, podem também ser decorrentes desse "apagão" na gestão das entidades a exemplo do ocorrido no SINTCOM-PR.

O presente artigo, longe de apontar uma solução definitiva, mostra um norte a ser seguido e alcançado, e embora o caminho para ele seja árduo, tortuoso e muitas vezes passe por paisagens novas e desconhecidas, existem infinitas estradas que levam ao destino pretendido: a gestão do conhecimento como um patrimônio de contínua valorização.

\section{REFERÊNCIAS}

BRANDT, Ricardo; TOSTA, Wilson. Era Lula consagra república sindical. O Estado de São Paulo, São Paulo, 05 abr. 2008. Disponível em: $<$ https://politica.estadao.com.br/noticias/geral,era-lula-consagra-republicaSindical,152028>. Acesso em: 13 abr. 2020.

BRASIL. Lei no 13.467, de 13 de julho de 2017. Altera a Consolidação das Leis do Trabalho (CLT) a fim de adequar a legislação às novas relações de trabalho. Brasília, DF: Presidência da República, [2017]. Disponível em: <http://www.planalto.gov.br/ccivil_03/_ato2015-2018/2017/lei//13467.htm>. Acesso em: 13 abr. 2020.

CHIAVENATO, Idalberto. Gestão de pessoas: o novo papel dos recursos humanos nas organizações. Barueri: Manole, 2015. 
DIEESE. Disponível em: <http://escola.dieese.org.br/escola>. Acesso em: 27 set. 2020.

EMPRESA BRASILEIRA DE CORREIOS E TELÉGRAFOS. Acordo coletivo de trabalho 2020/2021. Disponível em: $<$ https://www.google.com/url?sa=t\&rct=j\&q=\&esrc=s\&source=web\&cd=\&cad=rja\&uac $\mathrm{t}=8$ \&ved=2ahUKEwim9a-

G9InsAhWhHrkGHaG5CpUQFjAAegQIAxAB\&url=https\%3A\%2F\%2Fblog.correios.co m.br\%2Facordocoletivo\%2Fwp-content\%2Fuploads\%2F2020\%2F07\%2FACT-

20_21-.pdf\&usg=AOvVaw3Mk3a2J3M-thqXSWhKS5GV>. Acesso em: 27 set. 2020.

FLEURY, Maria Tereza Leme; FLEURY, Afonso. Construindo o conceito de competência. Revista de Administração Contemporânea, v. 5, ed. especial, p. 183196, 2001.

FUNDAÇÃO PERSEU ABRAMO. Curso de comunicação digital da FPA. São Paulo, 2020. Disponível em: <https://fpabramo.org.br/2020/06/03/conheca-o-cursode-comunicacao-digital-da-fpa-e-se-inscreva/>. Acesso em: 27 set. 2020.

GALVÃO, Andréia. A reconfiguração do movimento sindical nos governos Lula. São Paulo: Alameda Editorial, 2012.

ILAESE. Disponível em: <http://ilaese.org.br/>. Acesso em 27 set. 2020.

RATO, Marcelo.; MASSUELLA, Luana.; VERONESI, Gabriel. Sindicalismo implantado por Vargas não tinha poder de negociação. In: ALMEIDA, Lino. Jornal Rudge Ramos, São Bernardo do Campo, 2014. Disponível em: $<$ http://www.metodista.br/rronline/rrjornal/vargas-liga-Sindicato-a-governo> Acesso em: 18 abr. 2020.

RATO, Marcelo.; MASSUELLA, Luana.; VERONESI, Gabriel. Sindicalismo implantado por Vargas não tinha poder de negociação. In: FILHO, Ramos. Jornal Rudge Ramos, São Bernardo do Campo, 2014. Disponível em: 
$<$ http://www.metodista.br/rronline/rrjornal/vargas-liga-Sindicato-a-governo> Acesso em: 18 abr. 2020.

RODRIGUES, Lorena. Projeção do IPCA 2020 sai de 1,76\% para 1,59\%. O Estado de São Paulo, São Paulo, 23 set. 2020. Disponível em: <https://economia.uol.com.br/noticias/estadao-conteudo/2020/05/18/focus-projecaode-ipca-2020-sai-de-176-para-159-325-para-320-em-2021.htm 23/09/2020> Acesso em: 23 set. 2020.

RODRIGUES, Lorena. Focus: projeção de IPCA 2020 sai de 1,76\% para 1,59\% (3,25\% para 3,20\% em 2021). O Estado de São Paulo, São Paulo, 18 maio 2020. Disponível em: <https://economia.uol.com.br/noticias/estadaoconteudo/2020/05/18/focus-projecao-de-ipca-2020-sai-de-176-para-159-325-para320-em-2021.htm>. Acesso em: 25 set. 2020.

SOUZA, Jessé. A elite do atraso. Rio de Janeiro: Estação Brasil, 2019.

SPECTOR, Paul. Psicologia nas organizações. São Paulo: Saraiva, 2012.

Enviado: Novembro, 2020.

Aprovado: Janeiro, 2021. 